\title{
SISTEM ADMINISTRASI KLINIK HARAPAN IBU BERBASIS JAVA NETBEANS
}

\author{
Sumardi ${ }^{1}$, Ika Mei Lina ${ }^{2}$, Diyan Parwatiningtyas ${ }^{3}$ \\ Program Studi Informatika, Fakultas Teknik dan Ilmu Komputer, Universitas Indraprasta PGRI \\ Jalan Raya Tengah No 80, Kelurahan Gedong, Pasar Rebo, Jakarta Timur \\ sumardiyubi@gmail.com¹,ikameilina24@gmail.com², diane.tyas@gmail.com
}

\begin{abstract}
Abstrak
Penyebab kesulitan dalam mencari data pasien pada saat pendaftaran umumnya terjadi akibat dari pelayanan yang kurang efektif terutama pada klinik yang belum menggunakan sistem komputerisasi. Penelitian ini selain menganalisa juga bertujuan membuat sistem informasi pada klinik, agar kinerja terkait bagian pelayanan menjadi lebih efektif, sehingga memberikan pelayan terbaik terhadap pasien. Untuk metode penelitian yang digunakan adalah Kuantitatif Deskriptif dan teknik pengumpulan data dengan studi lapangan melalui pengamatan langsung dan wawancara fakta yang terjadi di lapangan serta studi kepustakaan untuk mendapatkan dan memperoleh informasi yang lebih akurat dan lengkap mengenai data yang dibutuhkan. Sehingga dapat disimpulkan bahwa hasil penelitian dengan dirancangnya sistem administrasi klinik Harapan Ibu yang dibuat menggunakan salah satu bahasa pemrograman yaitu Java dan database MySql, tentunya untuk meningkatkan efektifitas kinerja bagian-bagian terkait pelayanan seperti pada bagian pendaftaran, pemeriksaan serta pembayaran pada saat penginputan dan pencarian data serta dalam pembuatan laporan dengan begitu akan memberikan pelayanan terbaik dan mempermudah pasien untuk mendaftar saat berkunjung..
\end{abstract}

Kata Kunci : Java, Sistem Informasi, Administrasi, Klinik

\begin{abstract}
The cause of difficulty in finding patient data at the time of registration generally occurs as a result of less effective service especially in clinics that have not used computerized system. This research in addition to analyzing also aims to make the information system in the clinic, so that the performance related to the service is more effective, so as to give the best server to the patient. For the research method used is the quantitative deskriptif and data collection techniques with field studies through direct observation and interview of facts occurring in the field as well as literature studies to obtain and obtain more accurate and complete information about the data needed. So that it can be concluded that the results of the research with the clinic Administration System Harapan Ibu are made using one of the programming languages of JAva and MYSQL database, of course to improve the effectiveness of the performance related parts services such as in the registration, examination and payment at the time of input and search for data and in making reports so that it will provide the best service and make it easier for patients to register during a visit.
\end{abstract}

Keyword: Java, Information System, Administration, Clinic.

\section{PENDAHULUAN}

Menghadapi persaingan global serta berkembangnya ilmu pengetahuan dan kemajuan teknologi, sistem informasi berbasis komputer kini menjadi suatu hal yang wajib bagi pemenuhan kebutuhan informasi. Banyak bidang yang telah memanfaatkan sistem informasi berbasis komputer sebagai sarana untuk mempermudah pekerjaan, salah satunya dalam bidang instansi kesehatan. Informasi adalah data yang telah diklasifikasikan atau diolah dan diinterpresentasikan untuk digunakan dalam proses pengambilan keputusan (Sutabri, 2012). Klinik Harapan Ibu merupakan salah satu penyedia layanan kesehatan masyarakat, klinik ini melayani rawat jalan. Pada sistem yang sedang berjalan di klinik ini, semua data masih menggunakan sistem manual sehingga bagian pendaftaran mengalami kesulitan dalam proses pencarian data pasien. Karena prosesnya masih ditulis ke dalam sebuah buku besar yang disebut daftar kunjungan pasien, kemudian membuat kartu pasien. Proses pembayaran dan pembuatan bukti pembayaran masih manual sehingga dapat menyebabkan 
terjadinya kesalahan perhitungan maupun penulisan data. Selain itu proses pencarian data obat, pasien dan pembuatan laporan-laporan administrasi klinik masih sulit dilakukan.

Dari latar belakang masalah di atas, terlihat banyaknya kekurangan yang ditemukan dari sistem yang sedang berjalan secara manual, maka dibutuhkan suatu sistem baru yang dapat memperbaiki dan mengatasi kekurangan-kekurangan tersebut dengan dengan memanfaatkan teknologi komputer. Maka peneliti merancang Sistem Administrasi yang terkomputerisasi Pada Klinik Harapan Ibu. Menurut (Jogiyanto, 2010), perancangan adalah desain yang menentukan bagaimana suatu sistem akan menyelesaikan apa yang harus di selesaikan.Tujuan dari penelitian ini adalah untuk menganalisa sistem administrasi pada klinik Harapan Ibu agar kinerja bagian terkait pelayanan menjadi efektif, sehingga memberikan pelayanan terbaik terhadap pasien dan tidak terjadi lagi kesulitan dalam mencari data pasien. Dilanjutkan dengan merancang suatu sistem administrasi yang akan terkomputerisasi, agar tidak lagi membuat berkas atau dokumen secara manual dan membangun suatu sistem administrasi yang terintegrasi, mudah diakses, pada penginputan data dan penghitungan biaya pengobatan agar lebih efektif dan akurat. Sehingga dapat memudahkan proses pembuatan laporan yang benar dan lebih akurat kepada pemilik klinik

Manfaat dari penelitian ini diharapkan bisa menjadi bahan pertimbangan bagi pemilik klinik mengenai sistem administrasi yang akan dirancang untuk diaplikasikan agar lebih meningkatkan pelayanan terhadap pasien dan efektifitas kerja petugas terkait, seperti pada bagian Administrasi, Dokter dan Apoteker dalam proses kerjanya masing masing, yang mana selama ini masih menggunakan cara manual, dalam melihat dan membuat laporan dan diharapkan dapat dijadikan referensi untuk penelitian yang serupa untuk menambah pengetahuan dan ilmu serta bahan perbandingan, serta juga dapat dijadikan sebagai bahan pertimbangan untuk pihak atau peneliti yang berkeinginan mengembangkan sistem administrasi kliniknya.

\section{PENELITIAN RELEVAN}

Hasil penelitian terdahulu dapat dipakai sebagai acuan untuk melakukan penelitian selanjutnya. Meskipun ada perbedaan pada objek atau variabel yang di teliti. Penelitian tersebut dapat dijadikan sebagai gambaran bagi peneliti berikutnya untuk melakukan penelitian. Peneliti mendapatkan beberapa penelitian yang berkaitan dengan aplikasi olah data pada klinik. Pada penelitian pertama membuat aplikasi administrasi pasien pada klinik (Utami, 2015) dan penelitian kedua membuat aplikasi rawat inap (Sugiarti, 2015). Dari kedua peneliti tersebut, maka peneliti memutuskan untuk meninjau lebih lanjut kedua penelitian dari kedua peneliti tersebut yang dianggap relevan dengan penelitian yang bersangkutan. Kedua penelitian tersebut, yaitu Sistem Informasi Administrasi Pasien Pada Klinik Keluarga Depok dan Analisa Dan Perancangan Sistem Informasi Rawat Inap Pada Rumah Sakit Ibu Dan Anak Buah Hati Ciputat. Dari judul penelitian tersebut terdapat perbedaan metodologi penelitian yang akan dilaksanakan serta terdapat perbedaan objek penelitian. Oleh karena itu, peneliti akan meninjau lebih lanjut penelitian yang membahas mengenai administrasi menggunakan metodologi yang berbeda dan dapat mengembangkan aplikasi administrasi.

\section{METODE PENELITIAN}

Metode penelitian yang digunakan dalam penelitian ini adalah metode penelitian kuantitatif deskriptif yaitu dengan cara mencari informasi tentang gejala yang ada, didefinisikan dengan jelas tujuan yang akan dicapai, merencanakan cara pendekatannya, mengumpulkan data sebagai bahan untuk membuat laporan.

Tempat penelitian dan pengamatan dalam proses pengambilan data untuk pembangunan sistem, yakni pada Klinik Harapan Ibu Binong Permai, Curug, Tangerang, Banten. Serta teknik pengambilan data yang digunakan adalah studi lapangan yakni dengan pengamatan langsung dan wawancara serta studi kepustakaan agar mudah dalam perancangan sistem. Sedangkan metode pada perancangan sistem yang digunakan untuk penelitian ini yaitu metode waterfall, model waterfall merupakan salah satu model pengembangan perangkat lunak yang ada di dalam model SDLC (Sequencial Development Life Cycle) (Rizky, 2011). 


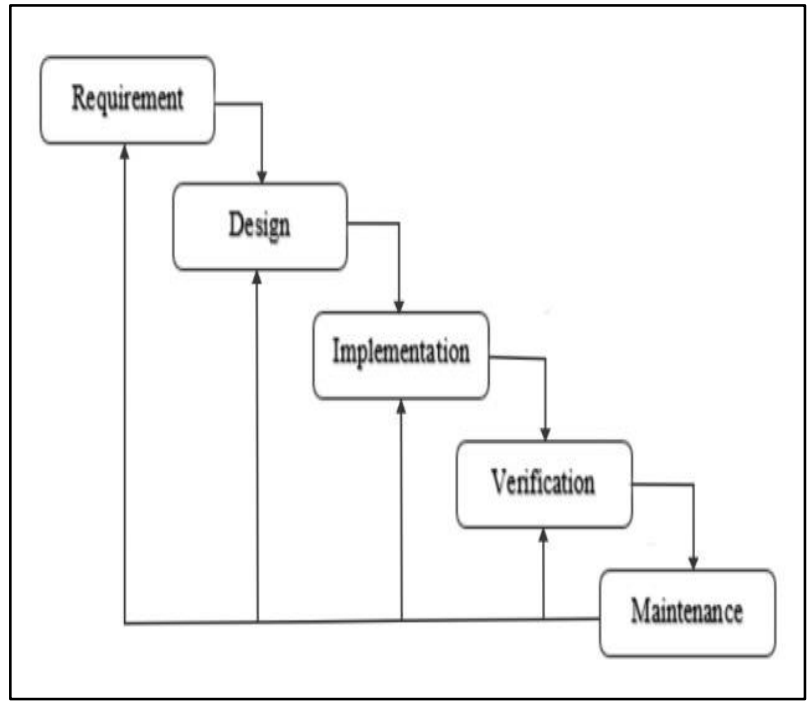

Gambar 1. Metode Waterfall

Meminimalisir kesalahan sistem jika menggunakan metode waterfall atau yang biasa disebut air terjun, tentunya proses pengembangannya harus melalui konsep yang sudah ditentukan, pertama melalui analisa kebutuhan (Requirement Analisis) dimana tujuannya pengguna dapat mamhami tentang perangkat lunak yang diinginkan dan mengetahui tentang batasan perangkat lunak tersebut. Desain (Design) membantu untuk menentukan perangkat-perangkat keras dan juga sistem persyaratan lainnya serta membantu memudahkan menjelaskan arsitektur sistem secara keseluruhan nantinya. Implementasi (Implementation) yaitu pada tahap ini kemudian sistem dikembangkan pertama kali di program kecil disebut dengan unit, dimana unit tersebut terintegrasi dalam tahap selanjutnya. kemudian Setiap unit akan diuji dan dikembangkan untuk mengetahui fungsionalitasnya sehingga disebut dengan unit testing. Verifikasi (Verification) Seluruh unit yang telah dikembangkan pada tahap implementasi kemudian diintegrasikan ke dalam sistem dan dilakukan pengujian pada masing-masing unit, akan dilanjutkan pngecekan setiap kegagalan maupun kesalahan dan memperbaikinya. Terakhir perawatan (Maintenance) pada perangkat lunak yang berhasil dijalankan dan sudah digunakan akan dilakukan pemeliharaan dan perbaikan. Pemeliharaan tersebut termasuk memperbaiki kesalahan atau error sistem yang tidak ditemukan pada saat pembuatan sistem. Sedangakan Perbaikan implementasi unit sistem bertujuan untuk meningkatan jasa dan kualitas sistem sebagai kebutuhan baru.

\section{HASIL DAN PEMBAHASAN}

Hasil dari penelitian pada Klinik Harapan Ibu nantinya akan dirancang sebuah sistem administrasi, tentunya untuk memudahkan dalam penginputan data dan penghitungan biaya serta pembuatan laporan. Karena sistem yang berjalan saat ini pada klinik Harapan Ibu masih banyak permasalahan yang terjadi. Dikarenakan sistem yang digunakan belum terkomputerisasi. Hampir semua yang berkaitan dengan pelayanan masih menggunakan cara manual sehingga kinerja bagian terkait tidak efektif dan menyebabkan kesulitan dalam proses pencarian data pasien, sehingga perancangan sistem administrasi pada klinik ini diharapkan bisa mengatasi permasalahan yang terjadi tersebut. Untuk lebih memahami fungsi yang ada didalam sistem tentunya harus menentukan diagram konteks terlebih dahulu. 


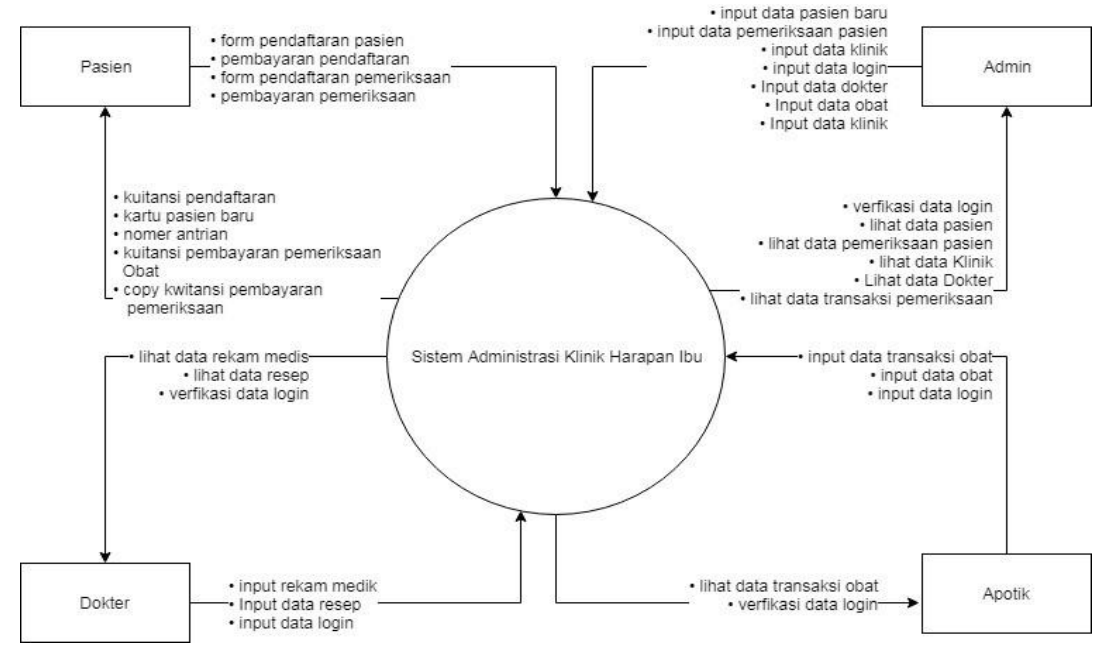

Gambar 2. Diagram Konteks

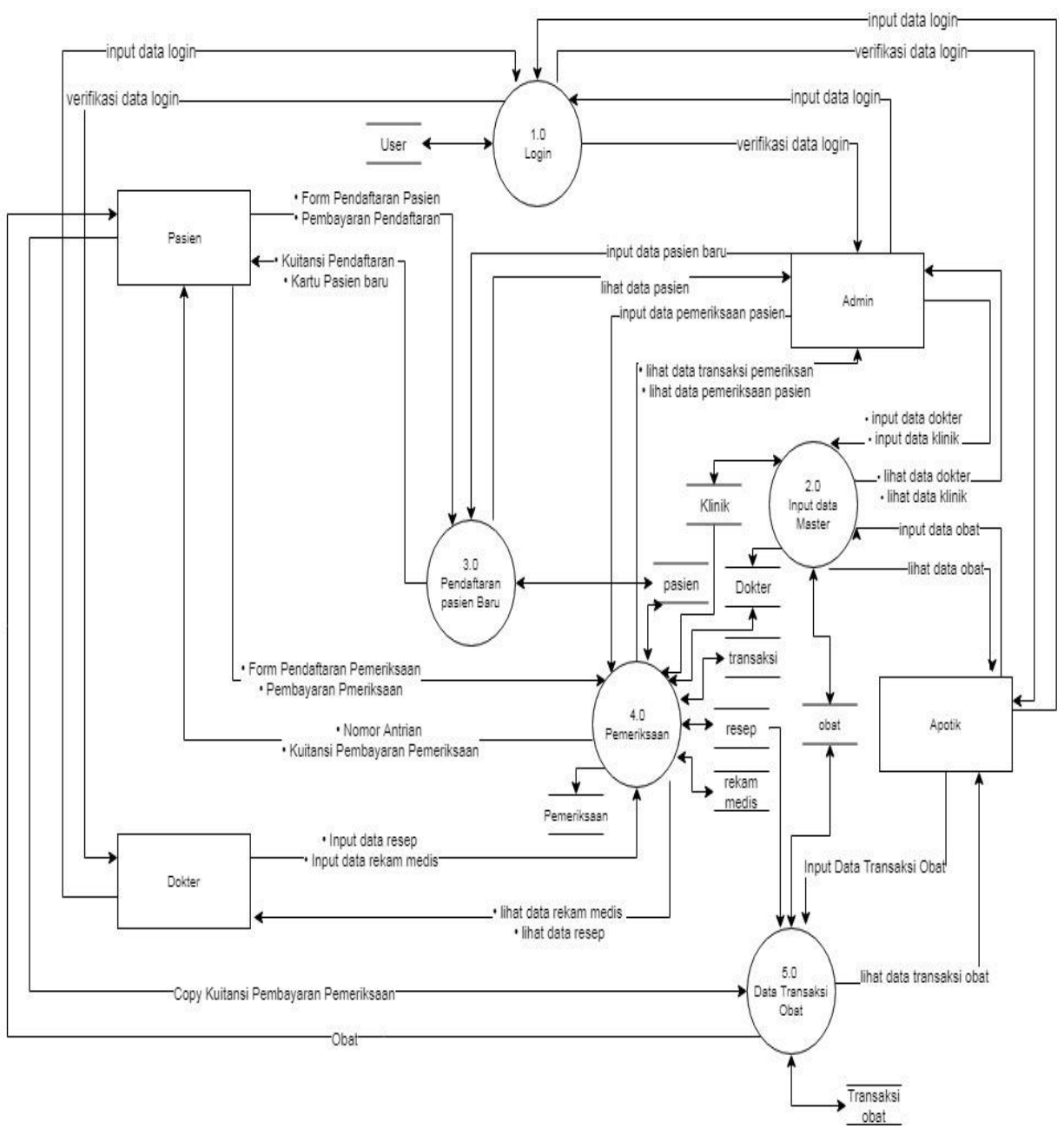

Gambar 3. Diagram Nol

Perancangan database meliputi Pembuatan entitas, Pendefinisian hubungan antar entitas dan Penerjemahan hubungan antar entitas. 


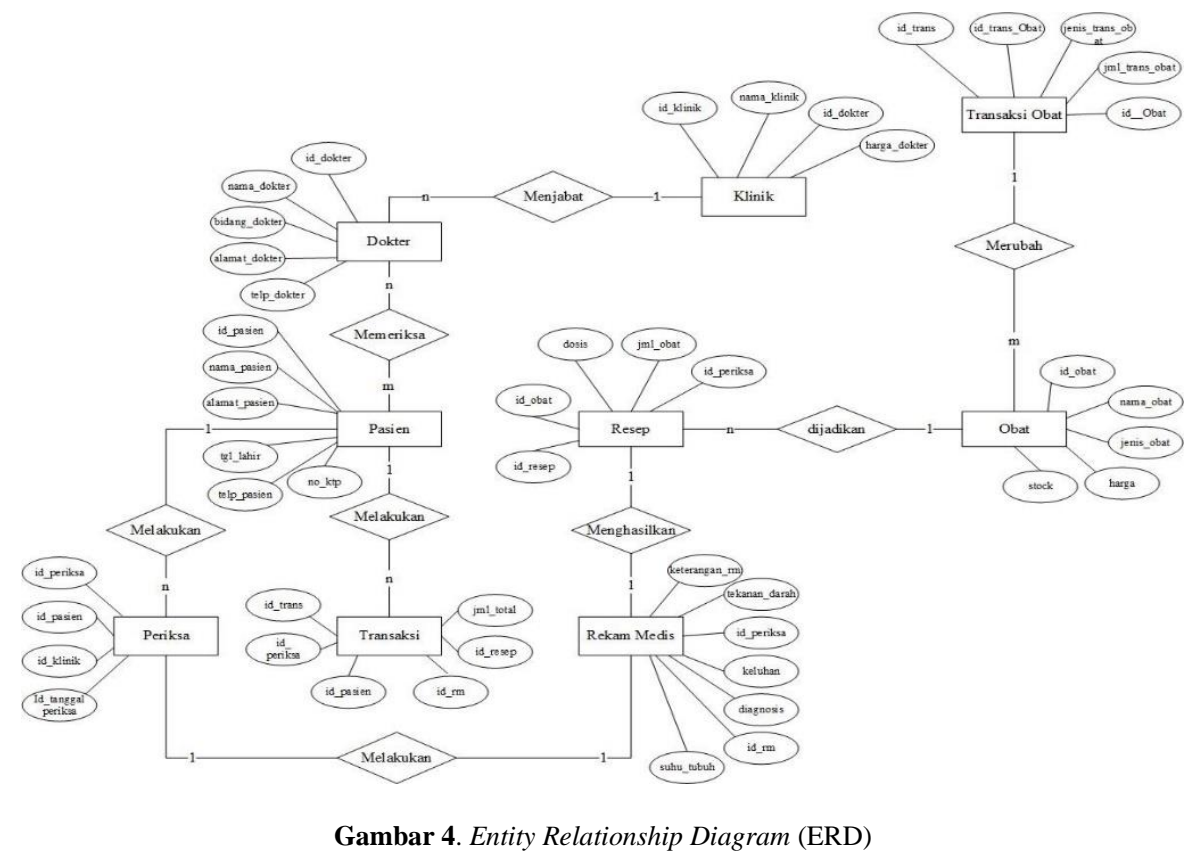

Setelah rancangan DAD dan database serta desain selesai maka dilanjutkan dengan pengkodean Pada perancangan Sistem Admistrasi Harapan Ibu ini peneliti menggunakan bahasa pemrograman Java yaitu bahasa pemrogrman berorientasi objek untuk mengembangankan aplikasi yang mandiri, aplikasi untuk perangkat cerdas yang dapat berkomunikasi melalui jaringan komunikasi atau internet. Untuk rancangan layar dan tampilan antar muka pada Klinik Harapan Ibu Binong Tangerang seperti berikut:

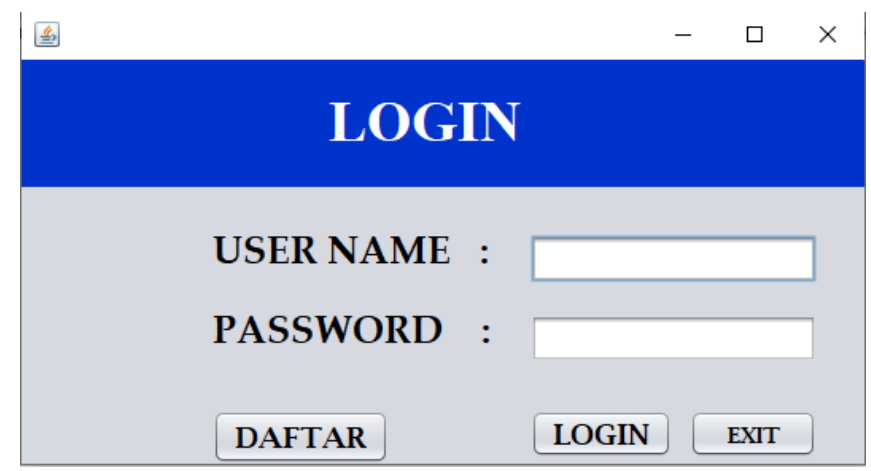

Gambar 5. Menu Login

Menu Login adalah menu yang pertama kali muncul saat program dijalankan. Dimana dari menu Login ditentukan tentang hak akses user yag nantinya menentukan menu apa saja yang bisa diakses pada saat masuk kedalam sistem. 


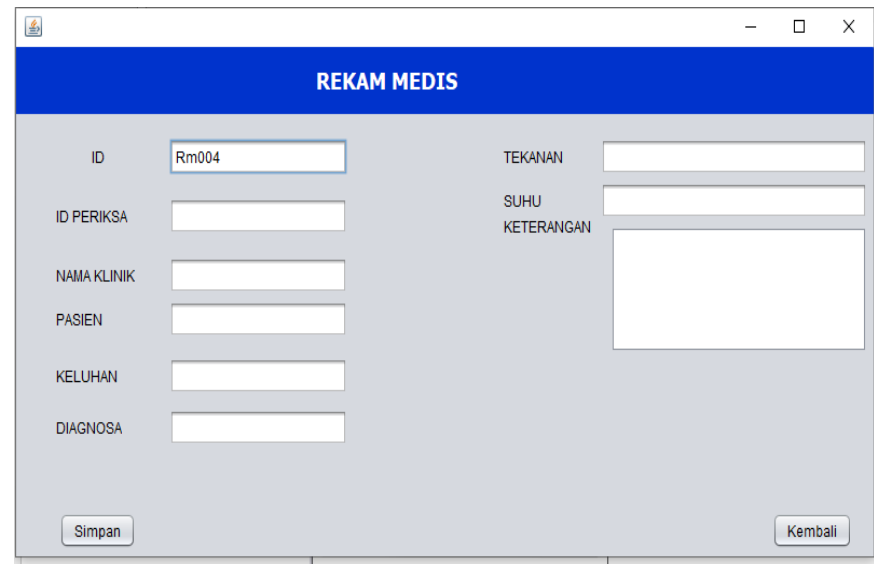

Gambar 6. Menu Rekam Medis

Pada menu rekam medis dokter melakukan dan menginput data diagnosa serta resep obat untuk pasien.

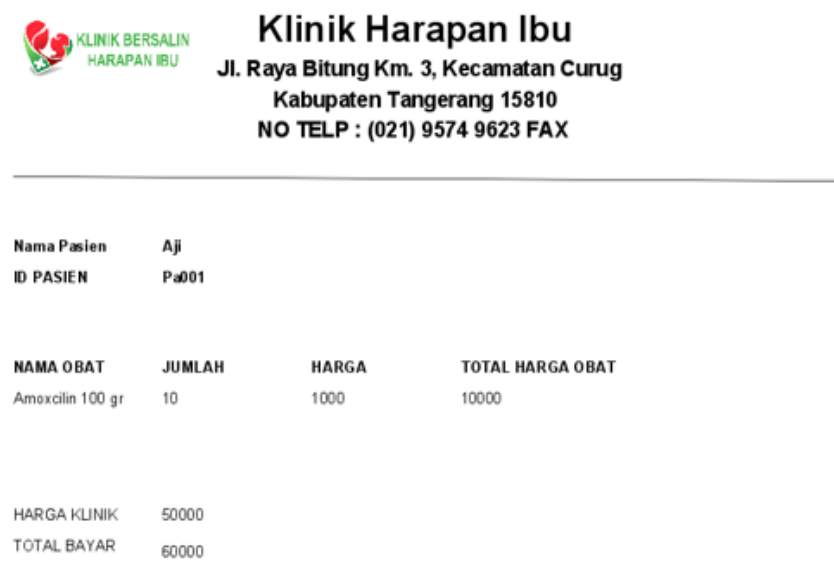

TANGGERANG, Jumat 20 Maret 2020

Gambar 7. Menu Bukti Pembayaran

Bukti pembayaran ini diberikan kepadaa pasien yang telah membayar biaya pengobatan serta sebagai syarat untuk bisa mengambil obat di apotek.

\section{SIMPULAN DAN SARAN}

Dapat disimpulkan dari hasil penyajian data diatas bahwa dengan dirancangnya sistem administrasi klinik Harapan Ibu berbasis dekstop dengan menggunakan bahasa pemrograman java diharapkan bisa mengatasi permasalahan-permasalahan pelayanan saat pasien berkunjung, seperti pada bagian pendaftaran, pemeriksaan dan pembayaran. Dan juga dengan adanya sistem yang telah terkomputerisasi dapat memudahkan dalam penginputan data dan penghitungan biaya serta pengolahan laporan dan dapat meningkatkan efektifitas kinerja bagian terkait pelayanan sehingga tidak lagi menyebabkan kesulitan dalam mencari data pasien.

Namun sebelum sistem administrasi ini diaplikasikan, terlebih dahulu user diberi penjalasan secara detail dan pelatihan mengenai proses kerja sistem yang akan di terapkan. Sehingga tidak terjadi kesalahan dan data yang sudah dimasukkan benar-benar bisa dipertanggung jawabkan. 


\section{DAFTAR PUSTAKA}

Jogiyanto. (2010). Analisa dan Desain Sistem Informasi. In Yogyakarta: Andi.

R. S. Pressman. (2010). Rekayasa Perangkat Lunak Edisi 7. In Teknoif.

Rizky, S. (2011). Konsep Dasar Rekayasa Perangkat Lunak. In Konsep Dasar Rekayasa Perangkat Lunak.

Sugiarti, Nuryasin, Y., \& Fitriani, N. (2015). Analisis Dan Perancangan Sistem Informasi Rawat Inap (Studi Kasus: Rumah Sakit Ibu Dan Anak Buah Hati Ciputat). Jurnal Sistem Informasi.

Sugiyono. (2017). Metode Kuantitatif. In Metode Penelitian Kuantitatif, Kualitatif, dan R\&D.

Sukamto, Ariani, R., \& Shalahuddin, M. (2013). Modul Pembelajaran Rekayasa Perangkat Lunak (Terstruktur dan Berorientasi Obyek).

Sutabri, T. (2012). Analisis Sistem Informasi. In Analisa Sistem Informasi.

Utami, L. A. (2015). Sistem Informasi Administrasi Pasien Pada Klinik Keluarga Depok. Konferensi Nasional Ilmu Pengetahuan Dan Teknologi. 